\title{
Effect of Salinity and Oxygen Condition on Phosphate Release from Marine Sediment Measured Using Diffusive Gradient in Thin Film (DGT) Technique
}

\author{
Askal Maimulyanti ${ }^{1, *}$, Budiawan $^{1}$, Asep Saefumillah ${ }^{1}$, and Heny Suseno ${ }^{2}$ \\ ${ }^{1}$ Department of Chemistry, Universitas Indonesia, Depok 16424, Indonesia \\ ${ }^{2}$ Marine Radiology Group, National Nuclear Energy Agency, Jakarta 12070, Indonesia
}

*Corresponding author:

tel: $+62-81320717396$

email:askal_m@yahoo.com

Received: May 2, 2018

Accepted: October 19, 2018

DOI: $10.22146 / \mathrm{ijc} .35233$

\begin{abstract}
The diffusive gradient in thin film (DGT) is an analytical technique to determine phosphate in the environment. This technique uses a thin film diffusive hydrogel in contact with a binding phase (ferrihydrite) to binding of phosphate. The released phosphate from marine sediment of Jakarta Bay was studied by DGT technique for effect of salinity and oxygen condition. Effect of salinity was observed by $\mathrm{NaCl}$ concentration from $0-35 \mathrm{~g} / \mathrm{L}$. The maximum phosphate release from sediment was occurred at the concentration of $\mathrm{NaCl} 30 \mathrm{~g} / \mathrm{L}$ with incubation for 15 days with phosphate released at $113.99 \mu \mathrm{g} / \mathrm{L}, M_{D G T}$ of $4.7723 \mu \mathrm{g}$ and $C_{D G T}$ of $17.56 \mu \mathrm{g} / \mathrm{L}$. The experiment showed the increase of $\mathrm{MgCl}_{2}$ and $\mathrm{CaCl}_{2}$ concentration reduced phosphate release from sediment. The condition of oxygen indicating the release of phosphate under anaerobic conditions is greater than the aerobic condition. The aerobic conditions with incubation for 21 days showed the release of phosphate from sediment to overlying water of 124.72 $\mu \mathrm{g} / \mathrm{L}, M_{D G T}$ of $2.4492 \mu \mathrm{g}$ and $C_{D G T}$ of $6.4380 \mu \mathrm{g} / \mathrm{L}$. Anaerobic conditions with incubation for 21 days showed phosphate release from sediment to overlying water of $208.62 \mu \mathrm{g} / \mathrm{L}$, $M_{D G T}$ of $6.1081 \mu \mathrm{g}$ and $C_{D G T}$ of $16.06 \mu \mathrm{g} / \mathrm{L}$. The experiment shows that salinity and oxygen concentration influences phosphate release from marine sediment of Jakarta Bay.
\end{abstract}

Keywords: phosphate release; DGT; salinity; oxygen condition

\section{- INTRODUCTION}

Phosphorus (P) is one of the most important nutrients for marine eutrophication. The eutrophication in the aquatic ecosystem causes significant changes in biodiversity. The eutrophication causes an increase in plant and animal biomass, the frequency of algal blooms, the growth of rooted plants, and decrease the species diversity [1]. Phosphate is the first cause of eutrophication in an aquatic system. It accumulates in sediments and under some environmental condition can be released into the water [2]. Monitoring phosphate concentration is very important to prevent and control eutrophication. The effect of eutrophication is rooted mainly in ecological impacts as decrease species biodiversity and abundance [3].

Sediment act as a sink where phosphate can be stored, and also as a source of phosphate for the overlying water and play an important role in the overall phosphate metabolism [4]. The release of phosphate from the sediments is an important source for the aquatic environment. Only dissolved phosphate can be released from the sediments to the overlying water. Release phosphate from sediment can be an important source of phosphate for the phytoplankton community in the water. If phosphate concentration is too high, algal growth may become blooming. Phosphate release from sediment is often the significant component of the phosphate budget of an aquatic system. Phosphate release is affected by a multitude of factors, such as $\mathrm{pH}$, redox potential, temperature, hydrological condition and oxygen concentration [5].

There are two main processes responsible for the regulation of phosphate exchange across the sedimentwater interface, i.e., sorption reaction between the sediment and porewater, and diffusive and connection movement between the pore water and overlying water 
column. By adsorbing phosphate or desorbing phosphate into the porewater, sediment act as a phosphate buffer in controlling solution phosphate concentration. On the other hand, the transport of dissolved phosphate between porewater and overlaying water occurs in various ways, with diffusive as the dominant mechanism [6].

Several studies have demonstrated release of phosphate from sediment [7-9]. Effect of $\mathrm{pH}$ and oxygen has been studying in sediment [10-12]. The past study showed phosphate released from lake and river sediment and used the conventional methods. The sediment was contact with overlying water for a certain time, and the phosphate released to overlying water was determined by the spectrophotometric method. In this research, we studied phosphate release by diffusion and accumulation of phosphate with DGT technique. The DGT technique is the new method to study the phosphate release from sediment for the effect of salinity and oxygen condition.

The DGT technique is based on a simple device which accumulates solutes on a binding agent (oxide gel) after passage through a hydrogel. The concentration of an analyte in solution as calculated using Fick's first law of diffusion and the measured mass of solutes accumulation to binding agent after a known deployment time [13]. The diffusive layer consists of the acrylamide gel which enables simple diffusive ions of the desired solute across the membrane to the binding gel. The binding materials have been particles of ion exchange resin or ion compounds that during the preparation of the binding phase usually settle along one face of the hydrogel [14]. The amount of analyte species that is accumulated within the binding phase under this condition is assumed to be equivalent to the amount of analyte that passes through the diffusive layer.

The purpose of the study reported in this paper was to investigate the effect of salinity and oxygen condition (aerobic and anaerobic) on the release of phosphate from marine sediment. Phosphate release was detected by the diffusive gradient in thin film (DGT) technique. In this research, we study the phosphate release from marine sediment of Jakarta Bay, Indonesia.

\section{- EXPERIMENTAL SECTION}

\section{Materials}

The DGT device with a diffusive gel of polyacrylamide and binding layer ferrihydrite, plastic molding were purchased from DGT research, Ltd (www.dgtresearch.com, England). Protective $0.45 \mu \mathrm{m}$ pore-size cellulose nitrate (Merck Millipore Ltd, Ireland), $\mathrm{NaCl}$ (Merck, Germany), $\mathrm{MgCl}_{2}$ (Merck, Germany), $\mathrm{CaCl}_{2}$ (Merck, Germany), $\mathrm{KH}_{2} \mathrm{PO}_{4}$ (Merck, Germany), $\mathrm{H}_{2} \mathrm{SO}_{4}$ (Merck, Germany).

\section{Instrumentation}

The instrumentation was Spectrophotometer UVVis (Perkin Elmer - Lambda 35, PerkinElmer, Inc. USA).

\section{Procedure}

\section{Sampling of sediment}

The sediment sample was collected from marine sediment of Jakarta Bay, Indonesia (106 34' 32. $6^{\prime \prime} \mathrm{E}, 06^{\circ}$ $01^{\prime} 24.2$ 'S) in January 2018. The sediment was collected using grab sampling, put into a sample box and stored at $4{ }^{\circ} \mathrm{C}$ until analysis.

\section{Assembling of DGT device}

The DGT device with the binding layer containing ferrihydrite was prepared as described previously [13]. The diffusive layer of the sampler consisted of a polyacrylamide hydrogel and protective $0,45 \mu \mathrm{m}$ poresize cellulose nitrate filter membrane. Standard pistontype DGT holder with a $2 \mathrm{~cm}$ diameter exposure window) was used to assemble the DGT device. A binding gel was placed on the bottom of the holder and was covered in order by a diffusive gel and $0.13 \mathrm{~mm}$ cellulose nitrate filter membrane. A piston-like plastic molding ion was used to support the gels and ensure that the single surface of this diffusion gel was in contact with the solutions. Scheme of DGT device shows in Fig. 1.

In this experiment, the phosphate in oxide-gel layer (ferrihydrite) was eluted using a known volume $\left(\mathrm{V}_{\text {acid }}\right)$ of $0.25 \mathrm{M} \mathrm{H}_{2} \mathrm{SO}_{4}$. The concentration of phosphate in acid (Ce) was measured by the spectrophotometric determination as phosphomolybdenum blue [13]. The 


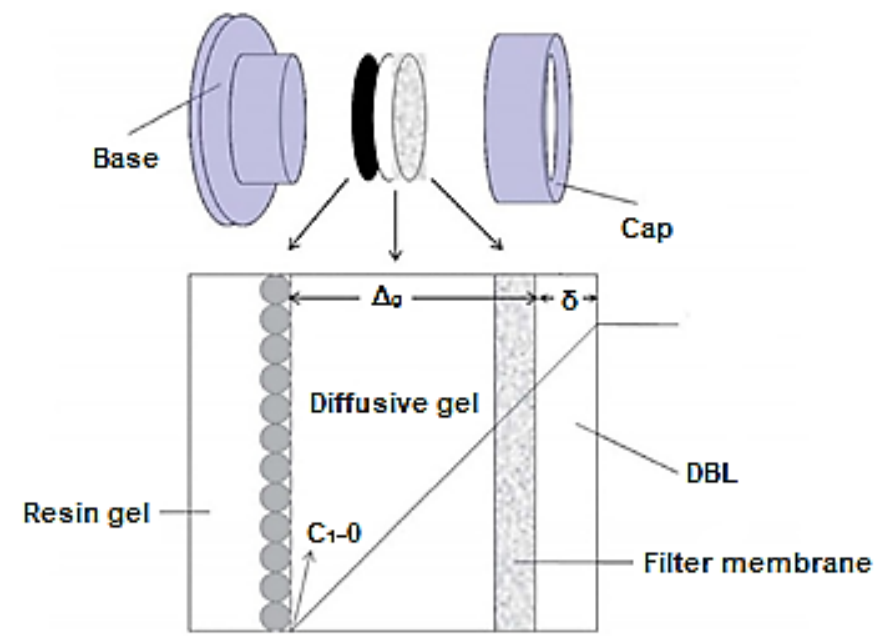

Fig 1. Scheme of DGT device [15]

mass of phosphate in the binding gel was calculated (Eq. (1)).

$$
\mathrm{M}=\mathrm{Ce}\left(\mathrm{V}_{\text {gel }}+\mathrm{V}_{\text {sulphuric acid }}\right)
$$

The volume of sulphuric acid was $5 \mathrm{~mL}$ and volume gel was $0.16 \mathrm{~mL}$

The phosphate diffuses in DGT device was calculated in the Eq. (2).

$\mathrm{C}=\frac{\mathrm{M} \Delta \mathrm{g}}{\mathrm{DtA}}$

$\mathrm{C}$ is the concentration of diffused analyte through the DGT device. $M$ can be obtained to direct measurement of phosphate species diffused through a known area (A) after a given time ( $\mathrm{t})$. The $\Delta \mathrm{g}$ was the thickness of the gel membrane and $\mathrm{D}$ is the diffusion coefficient.

\section{Phosphate release experiment}

Phosphate released experiment was performed in sampling tubes $(8 \mathrm{~cm} \times 24 \mathrm{~cm})$, the sediment depth in the tube was $4 \mathrm{~cm}$. The water was slowly added to the tube to the height of $8 \mathrm{~cm}$ to avoid sediment resuspension. The DGT device was put in overlying water. Orthophosphate in overlying water was monitored during the experiment period. The diffusion and accumulation of phosphate were determined in the DGT device.

\section{Effect of salinity on phosphate release}

Each tube contained $250 \mathrm{~g}$ of fresh sediment and $500 \mathrm{~mL}$ demineralization water. The salinity effect was studied by the concentration of $\mathrm{NaCl}, \mathrm{MgCl}_{2}$, and $\mathrm{CaCl}_{2}$. The concentration of $\mathrm{NaCl}(0,5,10,15,20,25,30$ and
$35 \mathrm{~g} / \mathrm{L}), \mathrm{MgCl}_{2}(0,5,10,15,20$, and $25 \mathrm{~g} / \mathrm{L})$ and $\mathrm{CaCl}_{2}$ $(0.5,1.0,1.5,2.0$, and $2.5 \mathrm{~g} / \mathrm{L})$. On the overlying water was put of DGT device and allowed to contact with the solution for 10 days. After 10 days the oxide-gel layer on DGT was eluted with $\mathrm{H}_{2} \mathrm{SO}_{4}$ and released phosphate concentration was determined by spectrophotometric method.

\section{Effect of aerobic and anaerobic condition on phosphate release}

Each tube contained $250 \mathrm{~g}$ of fresh sediment and $500 \mathrm{~mL}$ demineralization water. All experiment were incubated for 1-21 days and the sample was added $\mathrm{O}_{2}$ (aerobic condition) and bubbling $\mathrm{N}_{2}$ (anaerobic condition). The DGT device with oxide gel of ferrihydrite was put in overlying water. The phosphate in the overlying water was monitored during the experiment period. The diffusion and accumulation of phosphate were determined in the DGT device.

\section{- RESULTS AND DISCUSSION}

\section{Effect of Salinity on Phosphate Release from Sediment}

Salinity is one of the factors that influence of phosphate release from sediment to overlying water. The salinity can influence of phosphate release from sediment because the interaction between sediment and overlying water makes the ion exchange reaction between sediment and water. Effect of salinity was studied by variation of concentration from $\mathrm{NaCl}, \mathrm{MgCl}_{2}$, and $\mathrm{CaCl}_{2}$. The effect of $\mathrm{NaCl}$ used the range concentration of $0-35 \mathrm{~g} / \mathrm{L}$.

Fig. 2 shows the effect of $\mathrm{NaCl}$ concentration on released phosphate from sediment. $\mathrm{NaCl}$ concentration was varied from 0 to $35 \mathrm{~g} / \mathrm{L}$ with incubation for 5,10 and 15 days. Based on the experiment result, the increasing of $\mathrm{NaCl}$ concentration affected on the concentration of released phosphate from the sediment. The optimum concentration was obtained at salinity with a $\mathrm{NaCl}$ concentration of $30 \mathrm{~g} / \mathrm{L}$. The $\mathrm{NaCl}$ concentration of 35 $\mathrm{g} / \mathrm{L}$ resulted in a decrease of phosphate concentration in the overlying water. At the concentration of $\mathrm{NaCl} 0 \mathrm{~g} / \mathrm{L}$ and incubation time for 5, 10 and 15 days, the concentrations of phosphate release from sediment were 
$2.63,7.05$, and $46.58 \mu \mathrm{g} / \mathrm{L}$, respectively. The increase of $\mathrm{NaCl}$ concentration to $30 \mathrm{~g} / \mathrm{L}$, the phosphates release were $15.46,39.90$ and $113.99 \mu \mathrm{g} / \mathrm{L}$ for incubation of 5,10 , and 15 days respectively. The phosphate release from the sediment decreased when $\mathrm{NaCl}$ concentration was above $35 \mathrm{~g} / \mathrm{L}$. Due to saturation of the solution, the high concentration of $\mathrm{NaCl}$ led to the absorption of phosphate in the solution into the surface of the sediment. $\mathrm{NaCl}$ would react with the phosphate in sediment such as $\mathrm{Mg}_{3}\left(\mathrm{PO}_{4}\right)_{2}$ or $\mathrm{Ca}_{3}\left(\mathrm{PO}_{4}\right)_{2}$. The $\mathrm{Na}^{+}$ion replaces the $\mathrm{Mg}^{2+}$ ion or $\mathrm{Ca}^{2+}$ ion so that an ion exchange reaction occurs which causes the phosphate release. The higher the $\mathrm{NaCl}$ concentration, the more phosphate is released. But in certain condition with very high $\mathrm{NaCl}$ concentration, the $\mathrm{Na}_{3} \mathrm{PO}_{4}$ compounds became saturated and precipitated to the sediment.

The salinity of seawater was studied by varying the $\mathrm{NaCl}$ concentration of 10 to $35 \mathrm{~g} / \mathrm{L}$. DGT device is placed into the overlying water to accumulate released phosphate from sediment. In this study, there was an increase in the amount of phosphate mass accumulation to the added $\mathrm{NaCl}$ concentration. Fig. 3 showed the relationship of $\mathrm{NaCl}$ concentration to phosphate mass accumulation in the binding gel. The concentration of $\mathrm{NaCl}$ of $0 \mathrm{~g} / \mathrm{L}$ with incubation time for 5,10 and 15 resulted the accumulation of phosphate on the binding gel in DGT device of $0.0452,0.4672$, and 2,9196 $\mu \mathrm{g}$, respectively. Increasing $\mathrm{NaCl}$ concentration at $30 \mathrm{~g} / \mathrm{L}$ with incubation for 5,10 and 15 days caused an increase of phosphate accumulation on DGT device in the order of 0.4245 , 3.2224 , and $4.7723 \mu \mathrm{g}$, respectively. At the $\mathrm{NaCl}$ concentration of $35 \mathrm{~g} / \mathrm{L}$, there was a decrease in phosphate accumulation in the binding gel. The higher the salinity, the higher phosphate released from the sediment and caused the higher phosphate accumulated in DGT device. In the condition of very high salinity about $35 \mathrm{~g} / \mathrm{L}$, the sodium phosphate in the solution will be absorbed in the sediment that caused by the saturated of $\mathrm{NaCl}$ solution. A reduction in the amount of phosphate in the solution causes a decrease of phosphate accumulated in the DGT device.

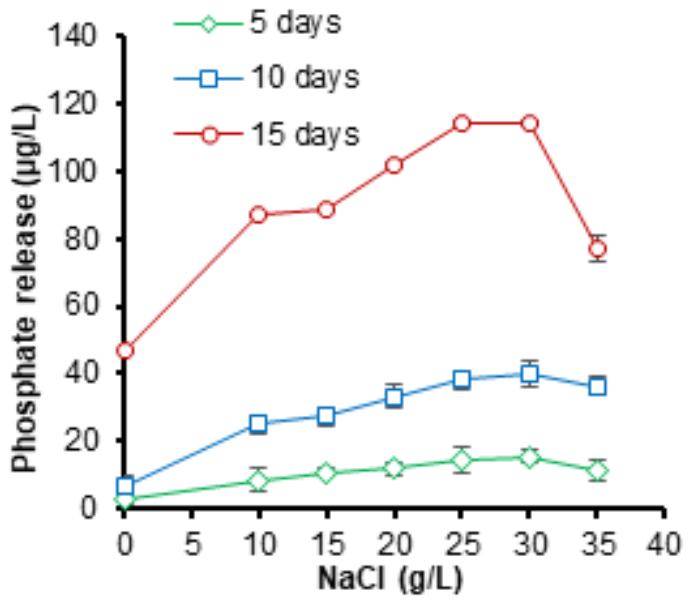

Fig 2. Effect of $\mathrm{NaCl}$ against released phosphate from sediment to overlying water

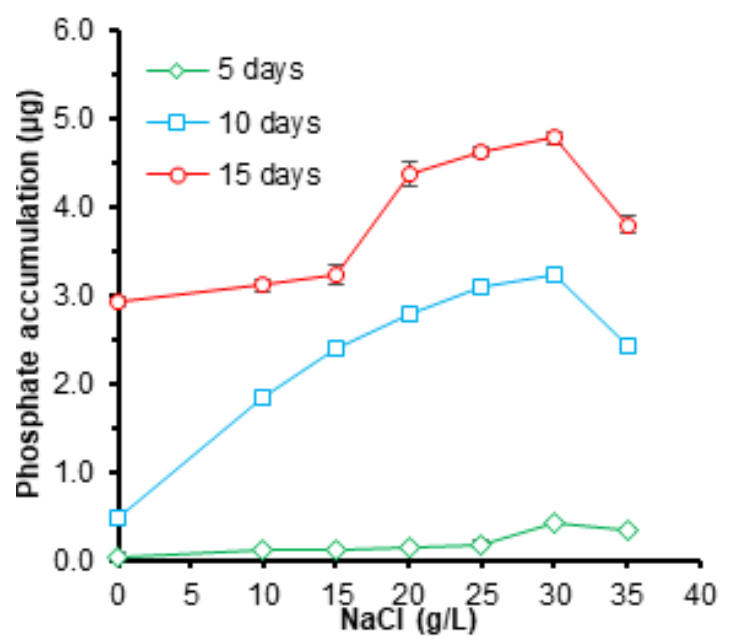

Fig 3. Effect of $\mathrm{NaCl}$ with phosphate accumulation in oxide-gel

The correlation between $\mathrm{NaCl}$ concentration with the phosphate diffusive to the DGT device $\left(\mathrm{C}_{\mathrm{DGT}}\right)$ has been shown in Fig. 4. The incubation for 5 days with a $\mathrm{NaCl}$ concentration of $0 \mathrm{~g} / \mathrm{L}$ showed the diffused phosphate concentration to DGT was $0.51 \mu \mathrm{g} / \mathrm{L}$. The concentration of $\mathrm{NaCl}$ to $30 \mathrm{~g} / \mathrm{L}$ increased $\mathrm{C}_{\text {DGT }}$ to 4.81 $\mu \mathrm{g} / \mathrm{L}$ and after concentration was over than $35 \mathrm{~g} / \mathrm{L}$, there was a decrease in the concentration of phosphate diffuse to the DGT device.

Incubation for 10 days with $\mathrm{NaCl}$ concentration of $0 \mathrm{~g} / \mathrm{L}$ resulted in a diffusion phosphate of $2.58 \mu \mathrm{g} / \mathrm{L}$. The $\mathrm{NaCl}$ concentration of $10 \mathrm{~g} / \mathrm{L}$ caused a significant 


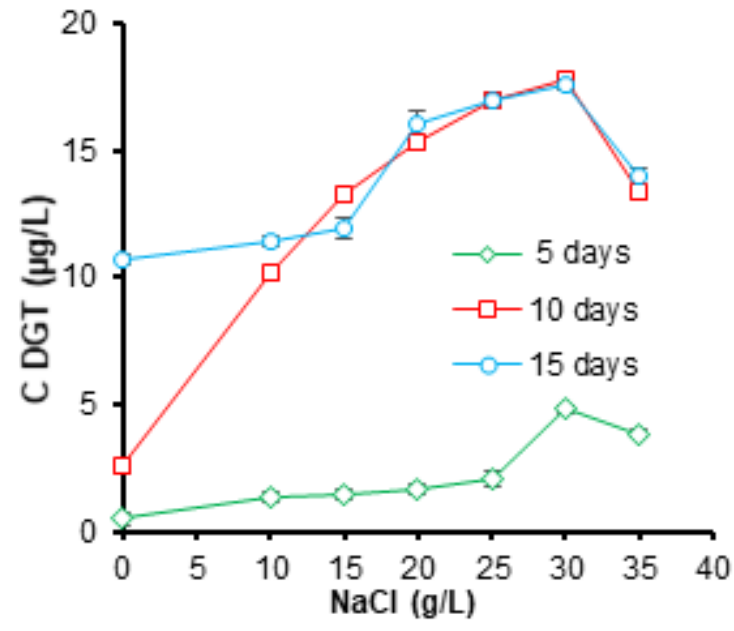

Fig 4. Effect of $\mathrm{NaCl}$ with phosphate diffusive to DGT device

increase in phosphate diffusion by $10.20 \mu \mathrm{g} / \mathrm{L}$. Incubation for 15 days with $\mathrm{NaCl}$ of $0 \mathrm{~g} / \mathrm{L}$ showed the presence of phosphate diffusive to DGT device of $10.74 \mu \mathrm{g} / \mathrm{L}$. After the $\mathrm{NaCl}$ concentration was increased to 15 and $20 \mathrm{~g} / \mathrm{L}$, there was no a significant increase in the phosphate concentration. The optimum phosphate diffusive occurred at a $\mathrm{NaCl}$ concentration of $30 \mathrm{~g} / \mathrm{L}$ with the obtained phosphate concentration was $17.56 \mu \mathrm{g} / \mathrm{L}$.

The $\mathrm{NaCl}$ concentration at $35 \mathrm{~g} / \mathrm{L}$ causes a decrease of the phosphate concentration which diffused into the DGT device. At the higher salinity than $35 \mathrm{~g} / \mathrm{L}$, the released phosphate will decrease due to saturated of the solution and sodium phosphate will be returned into the sediment. The effect was also caused by the higher $\mathrm{NaCl}$ concentration that will affect phosphate diffuse on the DGT device. Phosphate mobility and diffusion became slow and disrupted that caused by many ions in the solution. The salinity can affect the process of phosphate uptake in marine sediments. The low of salinity can increase the phosphate absorption process in the sediment [16]. This result is significant with the data obtained where the salinity is low then the release of phosphate is also small and it shows a larger sorption process. The salinity of seawater is influenced by the presence of major cations $\left(\mathrm{Na}^{+}, \mathrm{K}^{+}, \mathrm{Mg}^{2+}, \mathrm{Ca}^{2+}\right)$ and anions $\left(\mathrm{Cl}^{-}, \mathrm{SO}_{4}{ }^{2-}, \mathrm{HCO}_{3} / \mathrm{CO}_{3}{ }^{2-}\right)$. Increased of salinity can change the chemical equilibrium between the solution and sediment. This can change the ion activity coefficient. The

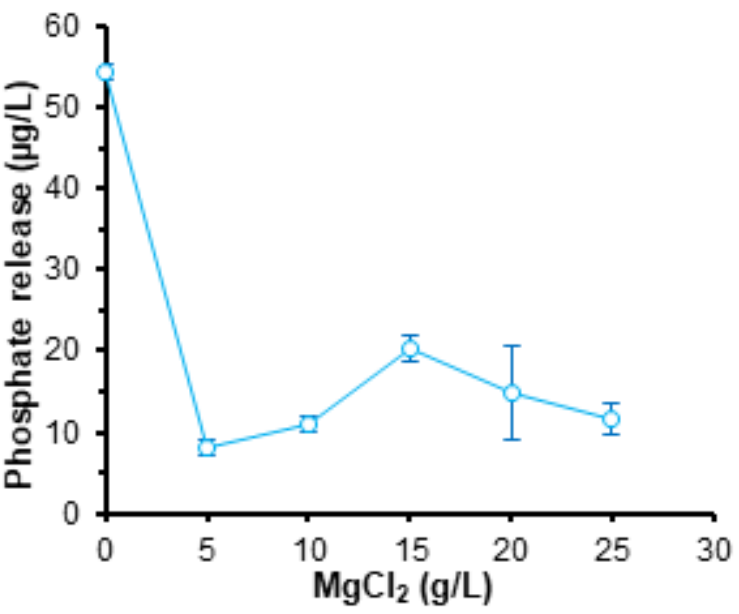

Fig 5. Effect of $\mathrm{MgCl}_{2}$ with phosphate released from sediment to overlying water

phosphate ion activity coefficient decreases with increasing of salinity from seawater. The presence of cations as the increase of salinity would compete with other ions resulting in desorption on the surface of the particle[17].

Fig. 5 shows the correlation of $\mathrm{MgCl}_{2}$ concentration to phosphate release from sediment. The experiment results showed that the increase of $\mathrm{MgCl}_{2}$ concentration reduced phosphate release from sediment. The $\mathrm{MgCl}_{2}$ concentration of $0 \mathrm{~g} / \mathrm{L}$ phosphate release from sediment was $54.38 \mu \mathrm{g} / \mathrm{L}$. The $\mathrm{MgCl}_{2}$ concentration was increased to $25 \mathrm{~g} / \mathrm{L}$ and phosphate release from the sediment decreased to $11.48 \mu \mathrm{g} / \mathrm{L}$. The phosphate species bound in the sediment was stable that might be caused by the presence of $\mathrm{MgCl}_{2}$ in solution, so that the phosphate release process can be controlled. The exchange reaction between phosphate in sediment with $\mathrm{MgCl}_{2}$ will form the $\mathrm{Mg}_{3}\left(\mathrm{PO}_{4}\right)_{2}$ which has a low solubility in the water. Because of the low solubility of the magnesium phosphate compound, it will reduce the phosphate release from sediment into overlying water. Salt-induced aggregation and flocculation of suspended matter are recognized as a major factor in the removal of particles from the water column, resulting in an increase in light penetration and may in an increased photo synthesis. The rate of clarification is enhanced by the presence of divalent cation (particularly $\mathrm{Ca}^{2+}$ and $\mathrm{Mg}^{2+}$ ) common in saline groundwater [18]. The increase of 


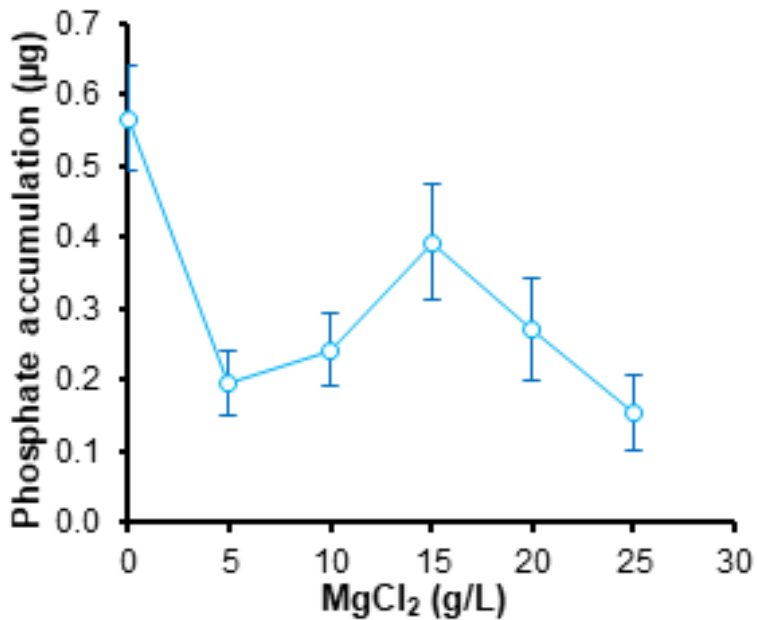

Fig 6. Effect of $\mathrm{MgCl}_{2}$ with phosphate accumulation in binding gel

water clarity, as a consequence of saline groundwater intrusion, has been the implication in the formation of significant blooms of cyanobacteria [19].

The correlation of $\mathrm{MgCl}_{2}$ to phosphate accumulated in the binding gel indicates that $\mathrm{MgCl}_{2}$ result in reduced of phosphate adsorption in the DGT device. The concentration of $\mathrm{MgCl}_{2}$ of $0 \mathrm{~g} / \mathrm{L}$ resulted in phosphate accumulation of $0.5674 \mu \mathrm{g}$. Increasing of $\mathrm{MgCl}_{2}$ concentration up to $25 \mathrm{~g} / \mathrm{L}$ decreased phosphate accumulation in the binding gel to $0.1551 \mu \mathrm{g}$. The correlation between $\mathrm{MgCl}_{2}$ concentration and phosphate accumulation causes a diffusion process and adsorption in DGT unit.

The effect of $\mathrm{MgCl}_{2}$ concentration to the diffuse phosphate in the DGT device showed that $\mathrm{MgCl}_{2}$ decreased the phosphate diffuse in the DGT device. The $\mathrm{MgCl}_{2}$ concentration of $0 \mathrm{~g} / \mathrm{L}$ resulted in phosphate diffusion of $3.13 \mu \mathrm{g} / \mathrm{L}$. The increase of concentrations of $\mathrm{MgCl}_{2}$ up to $25 \mathrm{~g} / \mathrm{L}$ decreased the phosphate concentration to $0.86 \mu \mathrm{g} / \mathrm{L}$.

The concentration of $\mathrm{CaCl}_{2}$ in solution causes a decrease in phosphate release from sediment. In the initial conditions using $\mathrm{CaCl}_{2}$ solution with a concentration of $0 \mathrm{~g} / \mathrm{L}$ resulted in phosphate release of $28.75 \mu \mathrm{g} / \mathrm{L} . \mathrm{CaCl}_{2}$ concentration was varied from 0.5 to $2.5 \mathrm{~g} / \mathrm{L}$ resulted in a decrease of the phosphate release from the sediment to $3.12 \mu \mathrm{g} / \mathrm{L}$. The significant decrease of $\mathrm{CaCl}_{2}$ concentration indicates that the phosphate in the sediment was stable with

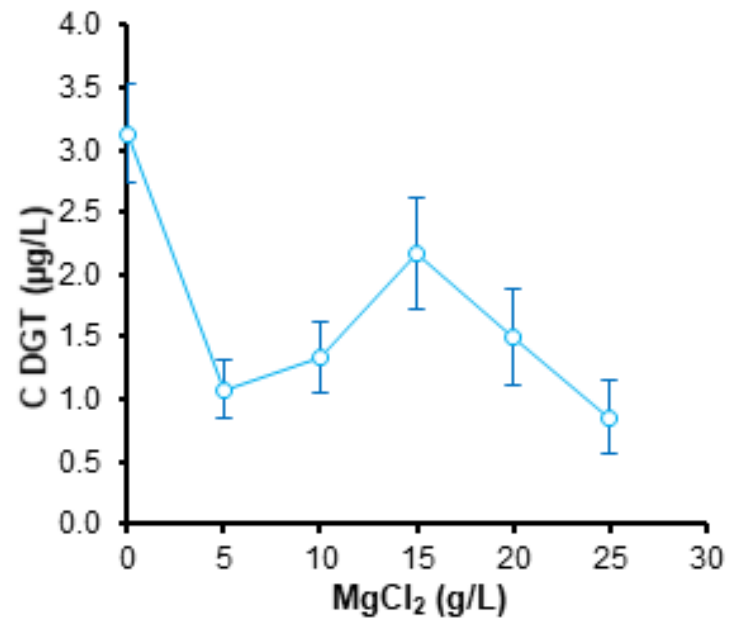

Fig 7. Effect of $\mathrm{MgCl}_{2}$ with phosphate diffusion to DGT device

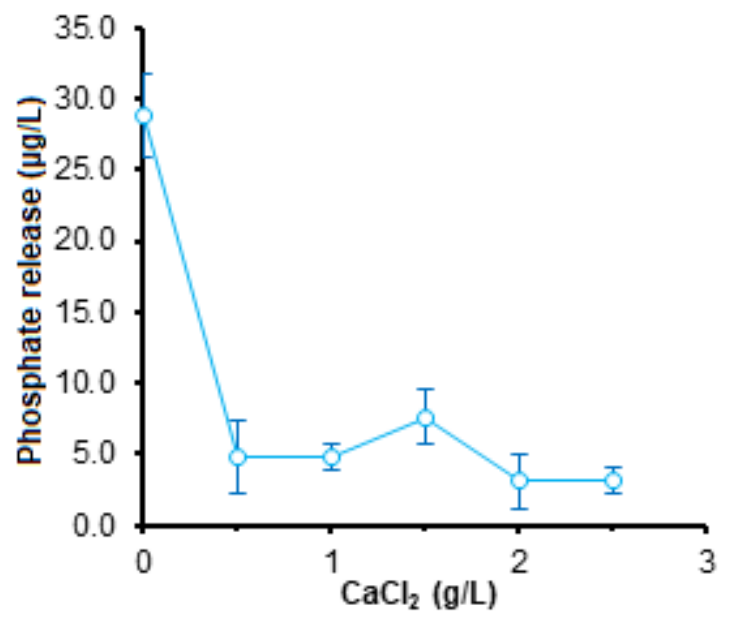

Fig 8. Effect of $\mathrm{CaCl}_{2}$ with phosphate released from sediment to overlying water

the presence of $\mathrm{CaCl}_{2}$ in overlying water. The phosphate bound with $\mathrm{CaCl}_{2}$ will form $\mathrm{Ca}_{3}\left(\mathrm{PO}_{4}\right)_{2}$ that has the small solubility in water and stable in the sediment.

The relative proportion of cations and anions in water change chemical equilibria and solubility of some minerals. The increasing ionic strength as a consequence of salinization can also disrupt chemical equilibria between dissolved and particulate phase. Either through changes to ion activity coefficients through salt ions blocking mineral surface adsorption site [17].

Fig. 9 shows the accumulated phosphate on the binding gel in the DGT device. The experiment result showed that the higher concentration of $\mathrm{CaCl}_{2}$ decreased the phosphate accumulation. The effect of phosphate 


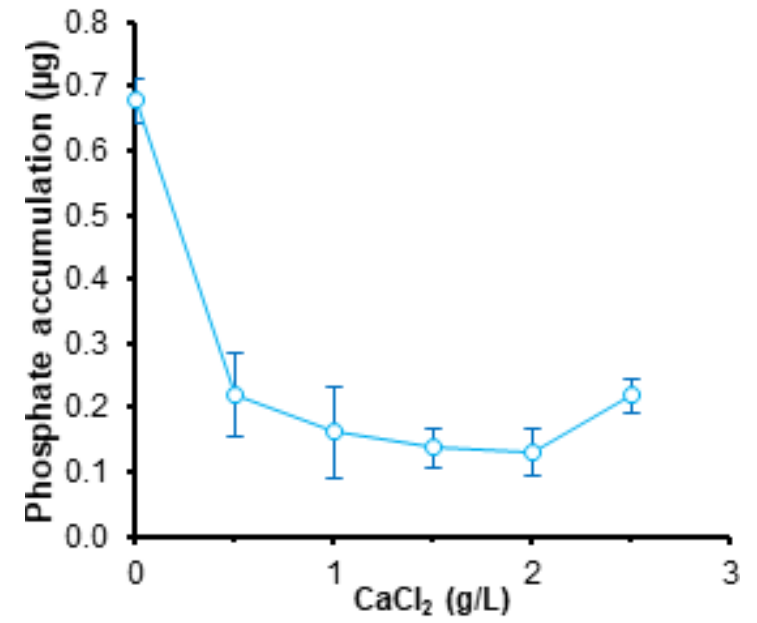

Fig 9. Effect of $\mathrm{CaCl}_{2}$ with phosphate accumulation in binding gel

accumulation is an indirect effect of phosphate release from sediment into overlying water. The $\mathrm{CaCl}_{2}$ concentration of $0 \mathrm{~g} / \mathrm{L}$ shows the accumulated phosphate of $0.6778 \mu \mathrm{g}$. The $\mathrm{CaCl}_{2}$ concentration of $2.5 \mathrm{~g} / \mathrm{L}$ shows the decrease of phosphate accumulated to $0.2190 \mu \mathrm{g}$.

As shown on Figure 10,the higher concentration of $\mathrm{CaCl}_{2}$ causes a decrease in phosphate diffusion to the DGT device. The effect of $\mathrm{C}_{\mathrm{DGT}}$ is indirect to the phosphate release from sediment into overlying water. The $\mathrm{CaCl}_{2}$ concentration of $0 \mathrm{~g} / \mathrm{L}$ showed a diffuse phosphate to DGT device of $3.74 \mu \mathrm{g} / \mathrm{L}$. The $\mathrm{CaCl}_{2}$ concentration of $2.5 \mathrm{~g} / \mathrm{L}$ indicates the decrease of phosphate diffuse to $1.21 \mu \mathrm{g} / \mathrm{L}$.

The activity coefficient of phosphate decrease with the increase of salinity that indicated the phosphate should be more soluble in saline solution than in fresh water. Surface chemistry may also be disrupted with increasing salinity as cations present in salt compete with other ions for desorption sites on particle surface [17]. The decrease of salinity caused the increasing of the phosphate adsorption in sediment [16]. As a result, there was a significant release of native adsorbed phosphate to seawater particularly in high salinity waters.

\section{Effect of Oxygen Condition to Phosphate Release from Sediment}

The effect of oxygen condition on phosphate release from sediment and phosphate absorption in the DGT unit is carried out by bubbling of $\mathrm{O}_{2}$ into the solution for

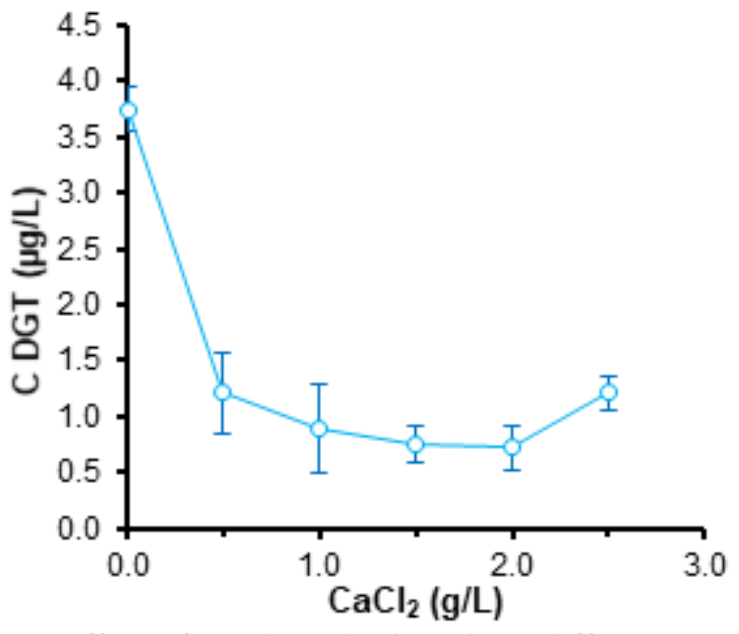

Fig 10. Effect of $\mathrm{CaCl}_{2}$ with phosphate diffusive to DGT device

aerobic conditions and bubbling of $\mathrm{N}_{2}$ to anaerobic conditions. The oxygen condition influences of the phosphate release because the oxygen condition (oxicanoxic) can exchange of potential redox from phosphate bound to the ion with have more than one valency such as iron and release from sediment to overlying water. During the incubation, the dissolved oxygen (DO) concentration in aerobic condition was from 7.14$9.60 \mathrm{mg} / \mathrm{L}$. Under anaerobic conditions the DO concentration is set below $1 \mathrm{mg} / \mathrm{L}$ with a range of 0.38 0.70 . The Phosphate release on aerobic and anaerobic conditions was performed with sediment incubation for 21 days.

Fig. 11 shows the effect of oxygen condition on phosphate release from sediment. A high oxygen concentration (aerobic) is carried out by bubbling $\mathrm{O}_{2}$ until DO concentration above $8 \mathrm{mg} / \mathrm{L}$. The anaerobic condition is carried out by bubbling of $\mathrm{N}_{2}$ and the DO concentration is below $1 \mathrm{mg} / \mathrm{L}$. The experiment result has shown that the released phosphate from the sediment under anaerobic conditions was higher than the aerobic conditions. The aerobic and anaerobic conditions were incubated for 1 to 21 days. The observations on aerobic conditions with incubation for 1 day showed the phosphate released from sediment was $9.23 \mu \mathrm{g} / \mathrm{L}$. The incubation was continued for 21 days resulting in an increase of the phosphate released of $124.79 \mu \mathrm{g} / \mathrm{L}$. The anaerobic condition shows a higher 


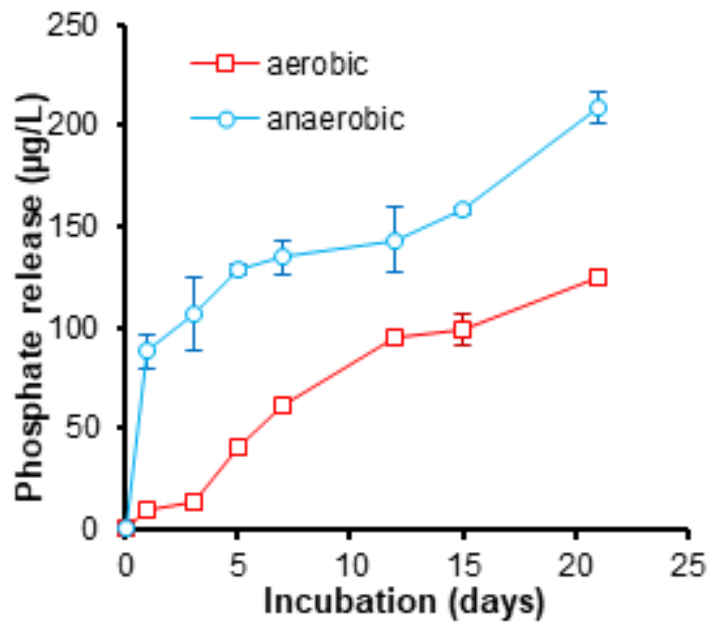

Fig 11. Effect of aerobic and anaerobic to phosphate release from sediment

concentration of phosphate than the anaerobic condition. The incubation for 1 day showed phosphate released of $88.11 \mu \mathrm{g} / \mathrm{L}$ and incubation for 21 days increased phosphate concentration to $208.62 \mu \mathrm{g} / \mathrm{L}$.

In aerobic condition, phosphate release in the sediment was limited by the high oxygen concentration in the overlying water. The phosphate release from sediment to overlying water is higher in anaerobic conditions than in aerobic conditions. In aerobic conditions, phosphates bound to $\mathrm{Fe}^{3+}$ as $\mathrm{FePO}_{4}, \mathrm{Fe}_{2}\left(\mathrm{HPO}_{4}\right)_{3}, \mathrm{Fe}\left(\mathrm{H}_{2} \mathrm{PO}_{4}\right)_{3}$. In this condition, the phosphate in overlaying water can be reabsorbed by $\mathrm{Fe}(\mathrm{OH})_{3}$ in the sediment so that the phosphate is difficult to release from the sediment. These results are consistent with previous studies that have been reported [20]. The condition of the oxygen deficiency (anaerobic) on phosphate release is influenced by the presence of iron ions in the sediments [21]. The anoxic (anaerobic) condition causes iron(III) wad reduce to iron(II). In the process of oxidation change, it can cause phosphate release from the sediment into the overlying water. The Fe(III) reduction can release of phosphate bound as Fe-bound $\mathrm{P}$ in the sediment [22]. The concentration of DO in sediment and overlying water is controlled by redox potential. The release of phosphate from sediment under anaerobic conditions can increase the amount of phosphate to the water system. This can increase eutrophication and oxygen demand in water and sediment. Because of the increased phosphate

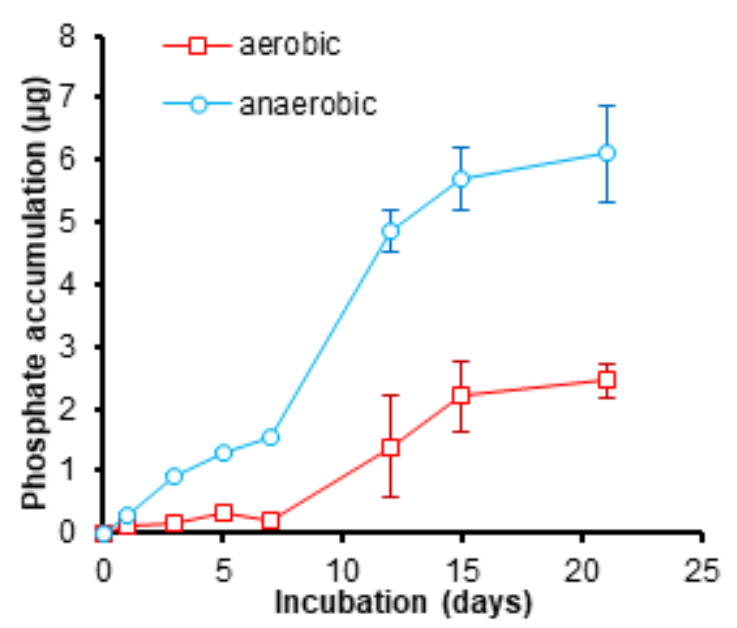

Fig 12. Effect of aerobic and anaerobic to phosphate accumulation in binding gel

concentration in the sediment due to the sedimentation process resulting in the rate of phosphate release also increased [23].

The effect of oxygen conditions on phosphate accumulation in the binding gel is shown in Fig. 12. The result of experiments shows that phosphates were more accumulated in binding gel under anaerobic conditions than aerobic conditions. The larger release of phosphate in solution in the anoxic (anaerobic) condition indicates that adsorbed phosphate on the binding gel is larger. Each of the aerobic and anaerobic conditions was performed incubated for 1 to 21 days. Observations on aerobic conditions with incubation for 1 day showed accumulated phosphate of $0.1013 \mu \mathrm{g}$. Incubation is continued until 21 days and the phosphate mass increases to $2.4492 \mu \mathrm{g}$. The incubation for 1 day showed accumulated phosphate mass of $0.2893 \mu \mathrm{g}$. Incubation for 21 days resulted in a phosphate mass increase of $6.1081 \mu \mathrm{g}$.

In the sediment, the phosphate can be interaction with iron makes the $\mathrm{FeO}-\mathrm{H}_{2} \mathrm{PO}_{4},(\mathrm{FeO})_{2} \mathrm{HPO}_{4}$ and $(\mathrm{FeO})_{3} \mathrm{PO}_{4}$. Speciation of iron in the sediment as $\mathrm{Fe}^{3+}$ in anoxic condition can reduce to $\mathrm{Fe}^{2+}$ with chemical reaction:

$$
\begin{aligned}
& \mathrm{FeO}-\mathrm{H}_{2} \mathrm{PO}_{4(\mathrm{~s})}+\mathrm{e} \stackrel{\text { anoxic }}{\longrightarrow} \mathrm{FeO}_{(\mathrm{s})}+\mathrm{H}_{2} \mathrm{PO}_{4}{ }_{(\text {aq })} \\
& (\mathrm{FeO})_{2} \mathrm{HPO}_{4(\mathrm{~s})}+2 \mathrm{e} \stackrel{\text { anoxic }}{\longrightarrow} 2 \mathrm{FeO}_{(\mathrm{s})}+\mathrm{HPO}_{4}{ }^{2-} \text { (aq) } \\
& (\mathrm{FeO})_{3} \mathrm{PO}_{4(\mathrm{~s})}+3 \mathrm{e} \stackrel{\text { anoxic }}{\longrightarrow} 3 \mathrm{FeO}_{(\mathrm{s})}+\mathrm{PO}_{4}{ }^{3-}{ }_{(\mathrm{aq})}
\end{aligned}
$$


Speciation of $\mathrm{H}_{2} \mathrm{PO}_{4}{ }^{-}, \mathrm{HPO}_{4}{ }^{2-}$ and $\mathrm{PO}_{4}{ }^{3-}$ can release from sediment to overlying water in anoxic condition. If the phosphate in sediment as $\mathrm{FePO}_{4}$ the reaction is:

$$
\mathrm{FePO}_{4(\mathrm{~s})}+\mathrm{e} \stackrel{\text { anoxic }}{\longrightarrow} \mathrm{Fe}^{2+}{ }_{(\mathrm{aq})}+\mathrm{PO}_{4}{ }^{3-}{ }_{(\mathrm{aq})}
$$

Fig. 13 shows the effect of aerobic and anaerobic conditions on phosphate diffusive to DGT device. In anaerobic conditions, the concentration of diffused phosphate was larger than the aerobic condition. In aerobic conditions for incubation of 1 day showed the concentration of phosphate diffusion of $5.5919 \mu \mathrm{g} / \mathrm{L}$. In anaerobic conditions for 1 day incubation showed a diffuse phosphate concentration of $15.8722 \mu \mathrm{g} / \mathrm{L}$. During incubation from 3 to 21 days, there is a fluctuation in phosphate concentration which diffuses to DGT device. Based on the experiment, there was no linear correlation between the incubation time of both aerobic and anaerobic conditions to the phosphate diffusing from the solution to the DGT device.

The aerobic condition is generally considered to promote phosphate uptake by sediments and anaerobic condition is conducive for release [24]. Iron and its redox play a major role in influencing and controlling phosphate exchange between the sediment and overlying water. In anaerobic condition, phosphate appears from the anaerobic bottom deposits, where it becomes trapped in the ferric complexes. When the oxidized microzone becomes reduced under anaerobic condition, the iron is then reduced to the ferrous form, with a concurrent release of phosphate to the overlying waters [23]. The suggestion mechanism for aerobic release phosphate is through the mineralization of organic phosphate. Desorption by chemical and biological processes of loosely bound phosphate as well as the mineralization of sedimentary organic phosphate was the mechanism for aerobic release. The phosphate concentration in the overlying water was higher in the anaerobic condition than in aerobic condition. Our result is consistent with those previous report that release occurred in the anoxic condition $[2,12]$. Oxygen deficiency is known to release phosphorus bound onto iron oxy(hydroxide). Ironbound to phosphorus is often considered the major internal source of phosphorus in the sea sediment [21]. Fig. 13 showed the phosphate in the sediment was released

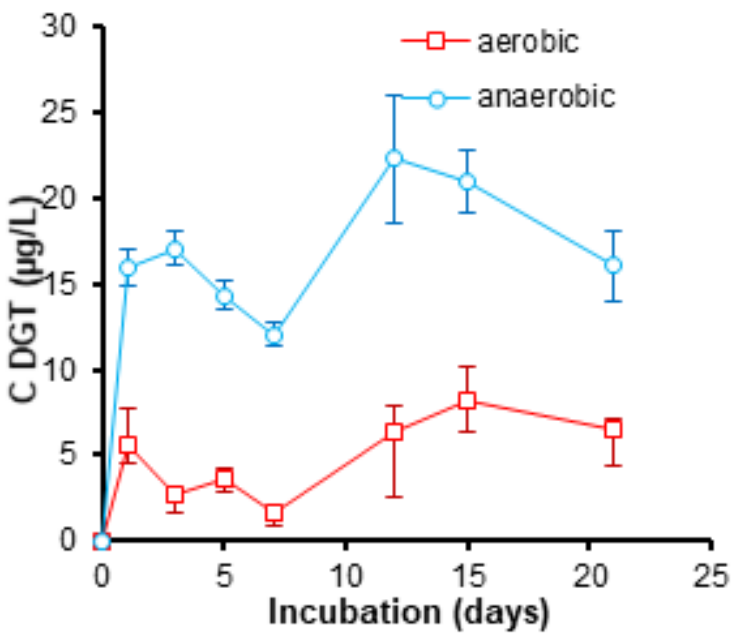

Fig 13. Effect of aerobic and anaerobic to phosphate diffusion in DGT device

to the overlying water in both aerobic and anoxic condition but the release quantity was different.

The aerobic condition, phosphate release in the sediments was limited by the high oxygen concentration in the overlying water which was not beneficial to algae growth [11]. These observations suggest that biological activities may also play a role in the increase in $\mathrm{pH}$ in the anaerobic system. The result is further supported by a previous study that the released phosphate from the sediments in the anaerobic condition was much more available to the alga growth than that in aerobic condition [11]. But in aerobic condition, phosphate release in the sediment was limited by the high oxygen concentration in the overlying water which was not beneficial to algae growth.

\section{- CONCLUSION}

The release of phosphate from marine sediment of Jakarta Bay was observed by the effect of salinity and oxygen condition. The detection of phosphate release used the new technique of diffusive gradient in thin film (DGT). The salinity effects were studied by variation of concentration from $\mathrm{NaCl}, \mathrm{MgCl}_{2}$, and $\mathrm{CaCl}_{2}$. The increase of $\mathrm{NaCl}$ concentration showed the increase of phosphate release from sediment. The maximum concentration showed at $30 \mathrm{~g} / \mathrm{L}$ of $\mathrm{NaCl}$. The effect of $\mathrm{MgCl}_{2}$ concentration from 0 to $25 \mathrm{~g} / \mathrm{L}$ and $\mathrm{CaCl}_{2}$ concentration from 0 to $2.5 \mathrm{~g} / \mathrm{L}$ showed the decrease of 
phosphate release with the increase of salt concentration. The effect of oxygen concentration was studied with added $\mathrm{O}_{2}$ (aerobic condition) and $\mathrm{N}_{2}$ (anaerobic condition). The anaerobic condition showed higher than the aerobic condition for phosphate release from sediment with incubation for 21 days.

\section{- ACKNOWLEDGMENTS}

We would like to thanks to Pusdiklat Industry (Ministry of Industry, Republic of Indonesia) for financial support of this study.

\section{- REFERENCES}

[1] Ansari, A.A., Gill, S.S., and Khan, F.A., 2010, "Eutrophication: Threat to Aquatic Ecosystems" in Eutrophication: Cause, Consequences, and Control, Ansari, A.A., Gill, S.S., Lanza, G., and Rast, W., (eds.), Springer, Dordrecht, 143-171.

[2] Gomez, E., Durillon, C., Rofes, G., and Picot, B., 1999, Phosphate adsorption and release from sediment of brackish lagoons: $\mathrm{pH}, \mathrm{O}_{2}$ and loading influence, Water Res., 33 (10), 2437-2447.

[3] Burns E.E., Comber, S., Blake, W., Goddard, R., and Couldrick, L., 2015, Determining riverine sediment storage mechanism of biologically reactive phosphorous in situ using DGT, Environ. Sci. Pollut. Res., 22, (13), 9816-9828.

[4] Boström, B., Andersen, J.M., Fleisher, S., and Jansson, M., 1988, Exchange of phosphorus across the sediment-water interface, Hydrobiologia, 170 (1), 229-244.

[5] Gao, L., 2012, Phosphorus release from the sediment in Rongcheng Swan Lake under different $\mathrm{pH}$ condition, Procedia Environ. Sci., 13, 2077-2084.

[6] Lai, D.Y.F., and Lam, K.C., 2008, Phosphorus retention and release by sedimentation eutrophic Mai Po Marshes, Hongkong, Mar. Pollut. Bull., 57 (612), 349-356.

[7] Wang, S., Jin, X., Zhao, H., and Wu, F., 2006, Phosphorus fractions and its release in the sediments from the shallow lakes in the middle and lower reaches of Yangtze River area in China, Colloids Surf., A, 273 (1-3), 109-116.
[8] Zhang, K., Cheng, P., Zhong, B., and Wang, D., 2012, Total phosphorus release from bottom sediments in flowing water, J. Hydrodyn. Ser. B, 24 (4), 589-594.

[9] Zhang, Y., He, F., Liu, Z., Liu, B., Zhou, Q., and Wu, Z., 2016, Release characteristics of sediment phosphorus in all fractions of West Lake, Hang Zhou, China, Ecol. Eng., 95, 645-651.

[10] Huang, Q., Wang, Z., Wang, C., Wang, S., and Jin, X., 2015, Phosphorus release in response to $\mathrm{pH}$ variation in the lake sediment with different ratio of iron-bound $\mathrm{P}$ to calcium-bound $\mathrm{P}$, Chem. Speciation Bioavailability, 17 (2), 55-62.

[11] Jiang, X., Jin, X., Yao, Y., Li, L., and Wu, F., 2006, Effects of oxygen on the release and distribution of phosphorus in the sediments under the light condition, Environ. Pollut., 141 (3), 482-487.

[12] Kim, L.H, Choi, E., and Stengstrom, M.K., 2003, Sediments characteristics, phosphorus types and phosphorus release rate between river and lake sediment, Chemosphere, 50 (1), 53-61.

[13] Zhang, H., Davison, W., Gadi, R., and Kobayashi, T., 1998, In situ measurement of dissolved phosphorus in natural waters using DGT, Anal. Chim. Acta, 370 (1), 29-38.

[14] Li, W., Zhao, H., Teasdale P.R., John, R., and Zhang, S., 2002, Application of cellulose phosphate ion exchange membrane as binding agent phase in the diffusive gradients in thin films technique for measurement of trace metal, Anal. Chim. Acta, 464, 331-339.

[15] Chen, C.E., Zang, H., and Jones, K.C., 2012, A novel passive water sampler for in situ samples of antibiotics, J. Environ. Monit., 14 (6), 1523-1530.

[16] Zhang, J.Z., and Huang, X.L., 2011, Effect of temperature and salinity on phosphate sorption on marine sediments, Environ. Sci. Technol., 45 (16), 6831-6837.

[17] Nielsen, D.L., Brock, M.A., Rees, G.N., and Baldwin, D.S., 2003, Effect of increasing salinity on freshwater ecosystem in Australia, Aust. J. Bot., 51, 655-665. 
[18] Grace, M.R., Hislop, T.M., Hart, B.T., and Beckett, R., 1997, Effect of saline groundwater on the aggregation and settling of suspended particles in a turbid Australian river, Colloids Surf., A, 120 (1-3), 123-141.

[19] Donnelly, T.H., Grace, M.R., and Hart, B.T., 1997, Algal blooms in the Darling-Barwon River, Australia, Water Air Soil Pollut., 99 (1-4), 487-496.

[20] Jiang, X., Jin, X., Yao, Y., Li, L., and Wu, F., 2008, Effect of biological activity, light, temperature and oxygen on phosphorus release processes at the sediment and water interface of Taihu Lake, China, Water Res., 42 (8-9), 2251-2259.

[21] Puttonen, I., Matilla, J., Jonsons, P., Karlsson, O.M., Kohonen, I., Kotilainen, A., Luckkari, K., Malmaeus,
M., and Rydin, E., 2014, Distribution and estimated release of sediment phosphorus in northern Baltic Sea archipelagos, Estuarine Coastal Shelf Sci., 145, 9-21.

[22] Wu, Z., Wang, S., Zhang L., and Jiao, L., 2016, DGT induced fluxes in sediments models for the simulation of phosphorus process and the assessment of phosphorus release risk, Environ. Sci. Pollut. Res., 23 (14), 14608-14620.

[23] Nürnberg, G.K., 1994, Phosphorus release from anoxic sediments: What we know and how we can deal with it, Limnetica, 10 (1), 1-4.

[24] Bates, M.H., and Neafus, N.J.E., 1980, Phosphorus release from sediment from Lake Carl Blackwell, Oklahoma, Water Res., 14 (10), 1477-1481. 